\title{
Hidden Orders and Preserving Tools of Heritage Fabric
}

\author{
Khawla K. Kawther ${ }^{1, *}$, Ghada Al Slik ${ }^{2}$ \\ ${ }^{1}$ Department of civil Engineering, University of Technology, Baghdad, Iraq \\ ${ }^{2}$ University of Baghdad, Baghdad, Iraq
}

Received December 12, 2020; Revised February 19, 2021; Accepted March 12, 2021

\section{Cite This Paper in the following Citation Styles.}

(a): [1] Khawla K. Kawther, Ghada Al Slik, "Hidden Orders and Preserving Tools of Heritage Fabric," Civil Engineering and Architecture, Vol. 9, No. 2, pp. 439-452, 2021. DOI: 10.13189/cea.2021.090217.

(b): Khawla K. Kawther, Ghada Al Slik (2021). Hidden Orders and Preserving Tools of Heritage Fabric. Civil Engineering and Architecture, 9(2), 439-452. DOI: 10.13189/cea.2021.090217.

Copyright $\bigcirc 2021$ by authors, all rights reserved. Authors agree that this article remains permanently open access under the terms of the Creative Commons Attribution License 4.0 International License

\begin{abstract}
Heritage cities are suffering from many and varied problems that they were unable to meet the current requirements, which made them an unfit environment for contemporary housing, causing a change in its residential functional structure, with the desertion of part of its indigenous population, and threatening the social and historical value of its urban fabric. There is great importance in preserving the urban heritage fabric in general. The research objectives are concerned with the heritage fabric in Al-Shawaka- Al-Karkh / BAGHDADIRAQ, in particular. This can be said to be the area of origin before the construction of the round city of Baghdad, and it has preserved its residential function through the ages; this makes it a special area for preservation and rehabilitation of the urban fabric in it .The research problem: The hidden orders and its relations to the preservation of architectural and urban. The research hypothesis: Each urban fabric has its own Orders. There are apparent Orders at the level of the urban fabric, at the same time, there are hidden Orders. It is necessary to study the hidden Orders of the heritage urban fabric, and understand them, which leads to find new tools in the way it is preserved, rehabilitated, and linked to the contemporary fabric. The research also deals with the difference between architectural preservation and urban preservation at the fabric level. When moving between alleys of Al- Shawaka, there is a neglected legacy on the large and small levels, the researchers analyzed these alleys to find hidden order. The methodology: studying the specificities of heritage urban fabric context historically and morphologically. The research aims to find Hidden Orders as well as the phenomenon Orders in the region and it aims to arrive at general indicators to preserve and rehabilitate them.
\end{abstract}

Keywords Hidden Order, Preserving, Heritage Fabric, Alley, Al-Shawaka, Al-Karkh, Baghdad

\section{Introduction}

In the past, the concept of heritage was in the scope of conservation considered with its monumental value, but in time heritage has started to be considered integrated with its environment after the many ideas were established in years and the necessity of the continuation of the "heritage identity" concept has been taken importance. [1] There are international preservation standards and charters that introduce principles for interventions in historical context, [2], but in in our country there are many problems in this issue.

The heritage fabric located in the heart of cities, especially in Iraqi cities, suffers from wear and tear, overcrowding, and a lack of services and infrastructure, [3] which made it vulnerable to removal at the earliest opportunity, just as most of the space patterns and the uses of the earth began to change as well, this led to an increasing demand for commercial uses in the heart of cities, which has negatively affected the housing stock and its urban fabric, causing gradual demolition and continuous disruption, and the absence of the contribution of this historical fabric serving the old city with its original function, even if there is a certain continuity of this tissue without changing the use of the land in it, the infrastructure and the nature of the services provided in it suffer from deterioration and regression. 


\section{The Methodology of the Research}

First, it was studied the historical background for the origin and emergence of the region, considering that it has hidden influences on the development of the region over time. In addition to the reality of the situation in the area, elect case study is Al-Shawaka, which is located in the old Karkh - BAGHDAD - IRAQ, the area is between the Al-Shuhada Bridge and Al-Ahrar and Haifa Street on the Karkh side.

Second: the analytical study, where the paths of Al-Shawaka area were analyzed, which are paths heading towards the river and hiding in its alleys a hidden wealth of various orders, patterns, and styles, through a field survey of the current reality of the area confined between Al-Shuhada bridge and Al-Ahrar on the Karkh side, using the camera, taking pictures and analyzing them, and finding hidden consistencies, on the level of architectural buildings, at the level of the urban fabric for the purpose of preserving it first thus, using these heritage orders in the designs of new cities in order to preserve the identity of the local city.

Third, inductive and deductive analysis was used to find variables from previous studies. See (figure 1).

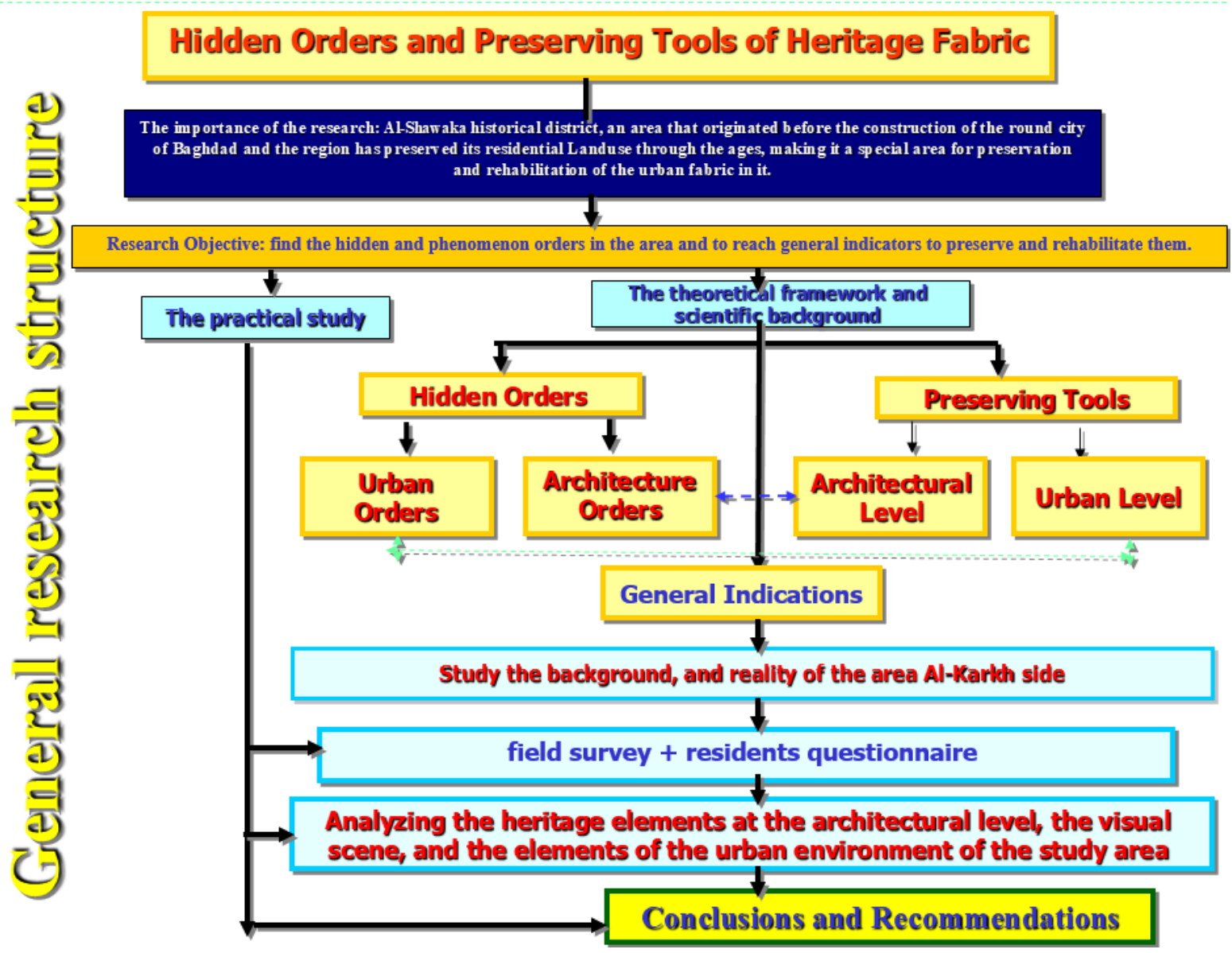

Figure 1. General research structure 


\section{Hidden Orders}

An order is a state governed by certain principles and rule, which stems from the human need for a methodology and guidance for any particular process, It is a state of the logical state of a group of relationships "governed by objectivity or subjectivity, which is characterized by basic concepts: complexity, legality, legality The degrees and levels of coordination depend on the type of relationships between the parts and the objective versus the subjectivity, as well as the degree of conformity in the principles of coordination of the group, It is the result of a set of (Boolean) rules, or objective for a specific group with characteristics.

The concept of a hidden order appeared in physics, and Bohm (1987) was the author of the hidden order theory, which indicates that particles are defined at every moment by hidden variables.[4]

(Holland, 1995) also defined the concept in computer software algorithms the hidden order as a state of adaptation that leads to complexity in nonlinear systems, which can be found through an understanding of the adaptive patterns that underlie their work and their increasing complexity that still exists in their basic nature.

Through the above, we conclude that the concept of the hidden order appeared in physics that particles are defined according to the circumstance of space and time, as well as that they are dynamic as found in the algorithms of computer software to indicate a state of adaptation and flexibility that leads to complexity, and that the order in financial transactions is a group of requests and hidden offers in financial and banking transactions, while in architecture and urban studies it is an order, which is a variable relationship between multiple variable levels, and that the hidden order is parted into small parts or is made up of small parts and thus has great effects, and it is on multiple levels, and of the various sizes and shapes, and varying priorities, as the concept in are abstract relationships that are intangible but variable and have great effects.

(Marten Kuilman, 2013)[5] claims the nature of space, which is the great mystery of architecture, that the description of vision is derived from the visible - invisible duality, he claimed that there is a quadrilateral division that is divided into four quarters, the first: space / time, the second: Partition, the third: time / space, and the fourth: movement, and this is a very general indication of the nature of these situations. Space is an abstract unit in which division occurs, and time is an invisible image, it indicates the existence of movement and, every communication is governed by natural variables above human capabilities.

(Bohm, 1987) and his student (Peat) also, [6] they created the concept of a generative order with reference to Fractal Geometry, and what this theory assumes is the possibility of generating an elementary form from a basic shape, based on the similar difference system. The shape changes according to a certain difference, for example, in the scale and the possibility of continuing to change it to infinity, and its complexity increases according to the different generations, such as the difference in appearance and direction, etc.

(Bohm) showed that the layers of the implicit order are invisible (the hidden) and that the change in the system of the relationship between the part and the whole occurs within the layers of the implicit system. What appears as a change in the system is nothing but the exposure of a new implicit layer (located below the level of total knowledge) and its transformation into a class Evidence with an implicit system in our minds, and it is a continuous process that will never stop.

Chaos theory also explained that complex paths can often be represented by simple dynamic models. Random behavior is described through unconscious levels of systems, given that those systems carry different degrees of clarity and complexity. This theory explains the struggle of forces is an inevitable condition for most structures in phenomena with advanced systems (such as spiral vortices in cosmic galaxies), and that every part of that movement is linked to each other through the actual part (action) and related to the rest of the parts, as well as the feedback feeds on forming Other additional parts are disturbed (relative to the context) as a result of conflict and contradictory parts of the system instead of their compatibility, which achieves discrimination and perception of the parts of the system as a result of the visual disturbance of the perceptual system of the recipient due to the lack of understanding or homogeneity. [6]

The main point in the implicit or hidden order is, in essence, that it is considered a basic order, while the apparent order is then understood as having been revealed through the implicit or the hidden order. [6] Thus, the basic movement of invisibility and appearance is a double movement in which there is ultimately no separation between invisibility and appearance. The movement has similar differences of degrees of invisibility and apparition.

It includes the Temporal Order, which appears at a certain point in time, and the other includes the Timeless Order, which is suitable for every place and time. An example of a radical change in the Overall Order can be found. It spreads in society in the transition from the Middle Ages to the present day, the view of the world in the Middle Ages is basically for a timeless order in which everything has its appropriate place, so that even the temporal order of history can be valid for every time and place. [6]

Through the above, it is possible to define The Hidden Order

It is the order that contains multiple layers in which the change occurs in the system of the relationship between 
the part and the whole, and every new change is nothing but exposure to a new implicit layer (located below the level of total knowledge) that is transformed into an evidence layer with a hidden system in our minds and that the process of transformations and changes is a continuous process that will never stop. The implicit or hidden order, in essence, is considered an essential order, while the apparent order is understood through the implicit or the hidden order. Thus, the basic movement of concealment and appearance is a double movement in which there is ultimately no separation between invisibility and appearance. The movement has different orders similar in degrees of invisibility and visibility.

\section{The Orders in Architecture}

The plan is a very old single (order) that started with parts of the building (columns and capitals), meaning components. The order appears by combining several parts to show at the end an integrated composition that has its uses. Through the combination and arrangement of a number of structural components, the order appeared, so the beginning of the appearance of the orders at the level of part of the building, the columns, and the crowns.

(Paul-Alan Johnson, 1994)[7] in his book Ordering Architecture, argued that Order is one of the main components in the architectural design process, deals in (Order, The Imposition of Human Constructs) with Order as an imposition in human buildings, and pointed out that most of the literature of classical architecture that it arose on the basis of order. The order was taken as a principle over analysis and it was found that it consisted of congruences or harmonies, repetition and a fixed ratio between parts, identity, and harmony. One of the important things for developing ideas is the order that represents the desire in the mind, nothing more, after it is said that beauty in "classical architecture" is composed of orders. So it can be said that the pattern in the design is much more beautiful than the buildings with the ugly decoration patterns, meaning that the pattern is beautiful by keeping the order at a high level, that is, a high degree, and it is that which clearly displays the proportions in the design. It consists of congruences or harmonies, repetition, and the constant ratio between parts, identity and harmony. Each generation feels a new type of prosperity standard, and it is exemplified by a new kind of idea of order.

The term came from the Latin word (ordin - ordo), meaning row, series or series, degrees, class or degree, and it is related to the word (ordiri) which means beginning and (ornare) which means decoration or jewelry. The word (ordinary) means distinct and unfamiliar, some unfamiliar events or things are one of the things that have changed within the establishment of the system or associated with it, any local organizations rule or law, and the organization is to put in place a system to prepare something or a person by imposing something. [7]
There are two Greek terms for the meaning of order: First: It is known in the Sanskrit language (Sanskrit) as (kosmos) as it refers to the order or organization of things. The (kosmos) means the adoption of human, animal and verbal motifs, which are decorations and decorations. Kosmetike, which is the art of dress and decoration, hence the English word "cosmetic". The second is (taxis) and means (the orderly arrangement of parts) organized arrangement of parts, a category, class or grade.

In the ancient Greeks, architecture consisted of arrangement, which not only involved in placing parts in relation to each other, but the elegance of the composition, and there were subcategories of arrangement and coordination, it called ideai in Greek, which means and which is represented in ground plan architecture plan, Elevation, and Perspective.

Vitruvius says that the order gives the necessary measures of detailed parts of the work taken, corresponding symmetrically with the overall proportions. The order is basically a balanced arrangement of work details separately, as well as proportions arranged in proportion to the symmetrical result. The concept is extended to include the sources that architecture considers the sources of natural inspiration and the nature of things, and then you will see architecture as a huge proposal of constructive works in ancient Greek culture. In traditional cosmetology, the word kosmos means order, that is, the interference of order in all areas of life.

The harmonic order consists of two modules: the first is the illusory world in Greek (Makeos kosmos), which is the "small world", and the other is a system that relies on the small parts, i.e. the great perfection of its small parts that are of the order. [7]

From the foregoing, we find the imposition and necessity of the order as a meaning for understanding in the world and that the order in architecture is a tangible design goal for an artificial goal, linking the order with the design idea through the floor plan, views, and perspectives.

In the history of architecture, it is one of the three original styles of Greek architecture characterized by the type of column and entablature used or a style developed from the three original three by the Romans, see (figure2) [8]
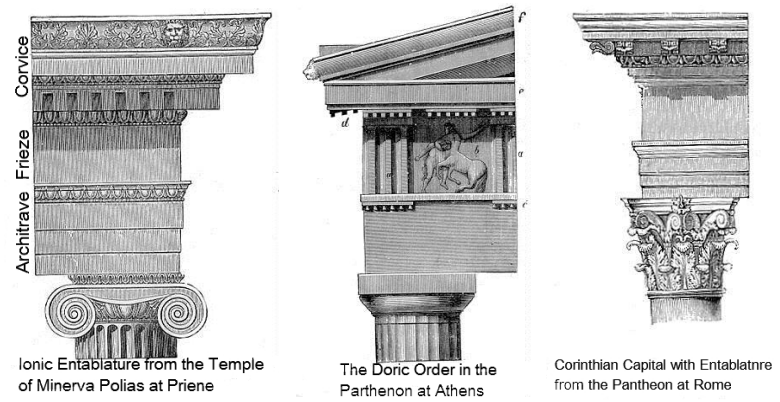

Figure 2. Represents the Ionic, Doric, and Corinthian column orders (Retrieved from https://en.wikipedia.org/wiki/Entablature) 
Louis I. Kahn (1955) [9] says in his paper (Order and Form) that the design is a form resulting from a process or manufacture in an order, the growth of the building in an order through a creative force, the nature of the space to be designed will reflect what will be, for example when the design of a hall, for example, is related to the formation of the hall and the way to hear it, or is it a hall as a creative tool, is it linked, for example, with specific symbols, or is it a traditional hall.

Find the pattern in terms of the order, there is a direct relationship between the beauty of the pattern and the high level of the pattern, the pattern appears through congruence or harmony and repetition in proportions and the fixed ratio between parts, identity and harmony.

\section{The Orders in Urban Design}

As (Hanson, 1989), the concept of order is less clear in urban design and is generally limited to observations related to engineering similarity or the presence of repetition observed either through the plan's vision of an urban area or the architectural treatment of its buildings. An orthogonal urban grid, or an engineered city, for example, is considered an ordered system. [10]

Arnheim (1972) [11] expresses the order and reduces it to the simple geometric form measured in favor of the basic physical function of an object. This definition has been colored by patterns of apparent geometric symmetry and harmony in natural forms and man-made settlements, however, it is understood to be indispensable for the operation of any system. Orders can be of any level of complexity. This definition highlights the inherent nature of order in any system. Having established the urban environment as a system consisting of man, time, and space, it follows that order is a necessary element in the environment and urban fabric.

The five elements of settlements identified by Doxiadis, provide the basic determinants of spatial order, however, these elements overlap with each other to add the spatial, social, cultural, and temporal dimensions of settlement. Difference and varying degrees of this interaction lead to diversity, "diversity" can be classified here in two distinct forms, arising because of that, it seems that some societies invest more in the physical patterns of space than others, while others have informal patterns. (Informal) and apparently organic only. The first type develops spatial patterns based on global justifications derived from mental thinking, while the second "organic patterns" express individual choices at the micro-level, but the question that arises is why these patterns should differ across different societies. "Can different types of society require different types of group control in order to be capable of this type of society?" [12]

This refers to the fact that settlements throughout the world do not differ from one another in physical formations but also in "the degree to which the arrangement of space appears as a clear dimension of culture. Therefore, the criteria for social culture lie in a major organizational force in urban agglomerations.

This view is further explained by Rappaport (1979), "The way in which cities, regions, and countries depend in the final analysis on the design of events for many individuals and groups at different times." Therefore, in order to study Fabric patterns, it is necessary to analyze the socio-cultural characteristics of the inhabitants. [13]

Human interaction with the environment results in a need to define space - a need arising from the desire to give order, meaning, and context to the diversity of events and actions known in space, human existence depends on the capacity and competence with which these events can separate activities into spatially defined boundaries - these boundaries being essential in generating social patterns and networks that in turn govern human behavior. The search for a meaning for space is, therefore, a necessary precondition for any exploration of the world of physical design

(Hanson, 1989), [14] study of the plans for the rebuilding of London after the Great Fire of 1666, "Order and structure in urban design" (doctoral thesis, A Morphological History of the City of London. (Hanson, 1989) work shows that an emphasis essentially on order, on the geometrical properties of plans, makes organic cities show up as disordered, chaotic systems.

Seemingly the main part of Hanson's article is her contention that, though engineers normally center around visual order by raising structure to a degree of cognizant investigation alongside order, a very much organized and liveable urban domain can be made.

As (Hanson, 1989), [14] when designing, whether it is a building, or an urban area, or an entire city, he uses the concepts of order to organize the plan: Hanson defines the order: it is mean using some principles based on some generally accepted ideas about sameness, repetition, geometry, grid, rhythm, symmetry, harmony and the like. These concepts can be perceived directly without the need for mediation, and they can be perceived as a whole simultaneously, roughly as gestalt.

Since order concepts are formal, they appear logical, and order concepts are one of the main means by which we perceive architectural imagination in action. There is a tendency to assume that order results in a structure in the empirical reality of buildings and places that we create through architectural means: structure, meaning making places understandable and clear through the creation of local differences that give a sense of identity (identity) and an understanding of the relationship between parts and the whole, so that we can reliably rely on the global form from any site within it. But order and structure are not the same thing at all.

As (Karimi, 2012), [15] (A reflection on Order and structure in urban design)، In the centre of city, where 
maximum interaction between all groups of people insiders and outsiders - is expected, this correlation is the highest, but when someone penetrates deep inside the residential areas, these correlations get weaker. It seems that the organic grid has created a mechanism through which certain parts of the grid, which need to be perceived and navigated more easily, become more intelligible. In contrast, in certain parts of the grid the level of intelligibility is reduced to make it harder for non-residents to find their way through the system, and thus discourages them to proceed farther. This hierarchy of the grid manifests itself in the size, shape and architectural articulation of different spaces as well. There is a clear change of all these factors when someone moves through the urban grid and explores places that are meant to play a local, an intermediate, or a city-wide role.

\section{Preserving the Heritage Fabric}

Preserving the architectural heritage is a global demand that all countries seek and compete for the preservation of this important part of their culture, especially in our era in which the world has become more like a cosmic village, which has increased the importance of architectural heritage as a physical embodiment of peoples' civilization and preserving it means preserving their identity Own, and physical proof of authenticity.

Preservation aims to:

- Understand the civilization that dominates the historical urban environments and integrate the content of the past with the components of the place, the legacies of time, its present and its future in a distinct unity that gives a sense of continuity.

- Deliver cultural, human and civilizational information that characterizes ancient cities and historical environments for future generations.

- The aim of preservation should not be prevention and maintenance only, or the exploitation of historical urban environments for tourism. Rather, people participating in the preservation process or popular participation must be invited to be the scientific and realistic key to all preservation processes. Several types of preservation can be distinguished:

\subsection{Preserving in the Urban Level}

Preserving urban heritage areas, including historical city centers, heritage areas from housing sectors and other activities such as commercial areas and reli Restorationgious areas, and preserving this level represents great support for historic city centers, especially in the prominent architectural structures in the city, because most of these facilities are linked Because of the emergence of the city.

Types of planning development:
Comprehensive Preservation Plan and Partial Renewal :

It includes giving full priority to preserving the heritage fabric and historical buildings, and it requires great efforts in providing basic services and not affecting the existing structures, but the realism of this solution is commensurate with the size of activities preserved within the heritage fabric, and the difficulty increases with the increase in the areas preserved.

\section{- A balanced preservation and development plan- :}

The use of balanced methods and solutions needs to compatible with the actual needs of the inhabitants of the heritage fabric.

It combines the preservation of the old fabric and the renewal of some of its parts, with a comprehensive redevelopment of other areas associated with areas of preservation and development. And the most peaceful plans in dealing.

The removal, demolition and comprehensive modernization plan- :

It includes the demolition and removal of most of the old urban fabric and heritage and historical buildings to ensure the provision of open spaces for the construction of a number of high-rise residential buildings and hotels around the site of the old area. However, this plan generates discontinuity with historical bonds (with the remaining features of the traditional fabric), and the negative impact of this proposal can be assessed by examining existing models and experiences in Medina and the cities of Mashhad and Karbala, where the only interest was in the numbers of visitors and meeting their needs, and caused isolation Complete with these buildings and create social, economic and logistical problems linked to the evacuation of old inhabited areas of homes, shops and service buildings linked to that fabric.[16]

\subsection{Preserving the Architectural Level}

It is the preservation of heritage or historical buildings individually and buildings of religious, civilizational, historical or architectural significance, and this type includes the preservation of individual or group buildings bearing historical heritage values and architectural and artistic aesthetic values. Consequently, the trend of preserving and protecting the vocabulary of the built environment of historical, cultural and symbolic value is based mainly on the rational balance between the values of modern development and the economic aspect. Among the methods of preservation are:

- Restoration: Restoration has many meanings, including restoring the building to its original state by rebuilding or repairing it, as the archaeological building undergoes over the passage of days to changes ranging from removing, modifying or adding parts to it, and these modifications change the 
architectural composition of the building, negatively or positively.[23]

- Maintenance: works to extend the life of the building and give it a good appearance, by which we limit any damage that may occur in the building by using appropriate means and methods such as repairing cracks, painting wood and metal, insulation of walls ... etc.

- Repair: It is the replacement of part or parts of the building due to the possibility of its collapse, and here it is necessary to use materials similar or similar as possible to the original construction materials of the building.

- Reconstruction: We cannot prejudice any archaeological building and rebuild part of it except in the event that part of it falls, so that we only leave the inevitability of renewal and reconstruction, especially in archaeological buildings of a distinctive architectural character.

- Renovation and rehabilitation: is the addition of modern things to the building, such as electricity, elevators, heating, etc. And these additions may cause damage to the building of varying severity. Therefore, engineers specializing in restoration work are very careful when dealing with such cases.[17]

There are many implicit classifications, other tools, and levels of intervention that integrate with what came above in relation to a single building or impact.

The preservation of the urban fabric differs from the preservation of individual buildings and edifices in many ways, as dealing with it comes at the level of the whole that includes parts with complementarity and interaction, and accordingly, the principles of urban renewal have emerged to complement the concept of preservation with interest in the transformations that are in line with contemporary requirements as well as with what happened in terms of changes. At the level of population and transportation methods, as well as the tariffs in the areas surrounding the fabric and the urban relationship between them, and according to the overall relationship of the basic plan of the city, with reference to the overall vision of the city and the heritage fenced areas in particular. Therefore, before starting to put forward the tools of urban preservation, a large and multi-faceted data collection process takes place, including:

- Studying population, demographics, population densities, occupations, and cultural levels.

- Studying the current reality of the fabric in terms of renewable uses, structural and architectural levels, building heights, and diagnosing and recording conservative components.

- Studying the old and new paths in the fabric, the connecting ways of transportation, and the main contiguous and implicit movement nodes.
Studying the existing health, educational and community services, and the volume required of them.

- Studying the edges of the surrounding sides and analyzing their future capabilities

- Studying the infrastructure, laying it out, and the tools for updating it without prejudice to the heritage fabric.

- Studying and evaluation of the levels of individual buildings (parts) of the fabric and their classification according to the architectural and construction levels.

- Determining the paths that represent the main and main axes of the movement and the possibilities of their integration with the new surrounding axes are

- Determining the spaces (heritage spaces) that represent basic components and elements in the fabric structure to preserve and develop them into public spaces.[18]

- Diagnosing the sites and areas of dilapidated buildings, and determining the types of urban dictation appropriate for each of them

- Determining indicators for preserving the urban landscape and installing façade preservation controls when needed to rebuild the rest of the building

- Determining the new used that can be occupied by buildings of complete preservation or urban infill to continue the fabric life and to leave some contemporary functions in it or for specific tourism and cultural uses.

- Eliminating emergency uses that are inconsistent with the continuity of the heritage fabric and its future vision within the city.

According to the above indicators, the following practical study was carried out in Al-Shawaka neighborhood.

\section{The Practical Study}

\subsection{Description of Historical District}

Al-Shawaka area is located on the Tigris River, bordered to the north by (Bab Al-Seef locality), and to the south is the locality (Al-Kuraimat), meaning that these three old Baghdad stores are located in the area between the Al-Shuhada Bridge and Al-Ahrar Bridge. Today the region has its three stores. It is called Al-Shawaka.

Al-Shawaka is a popular heritage area from Baghdad's Al-Karkh area, classified as a heritage residential area according to the Paul Service Map of Land Use, located between the Al-Shuhada Bridge and the British Embassy, the local numbering is Mahalla (218). The whole area is an authentic and ancient Baghdad region dating back to the Abbasid era, see (figure 3, 4, 5). 
Table 1. Shows the research indicators of Hidden \& visual orders to Preserving Heritage Fabric/source: the researchers

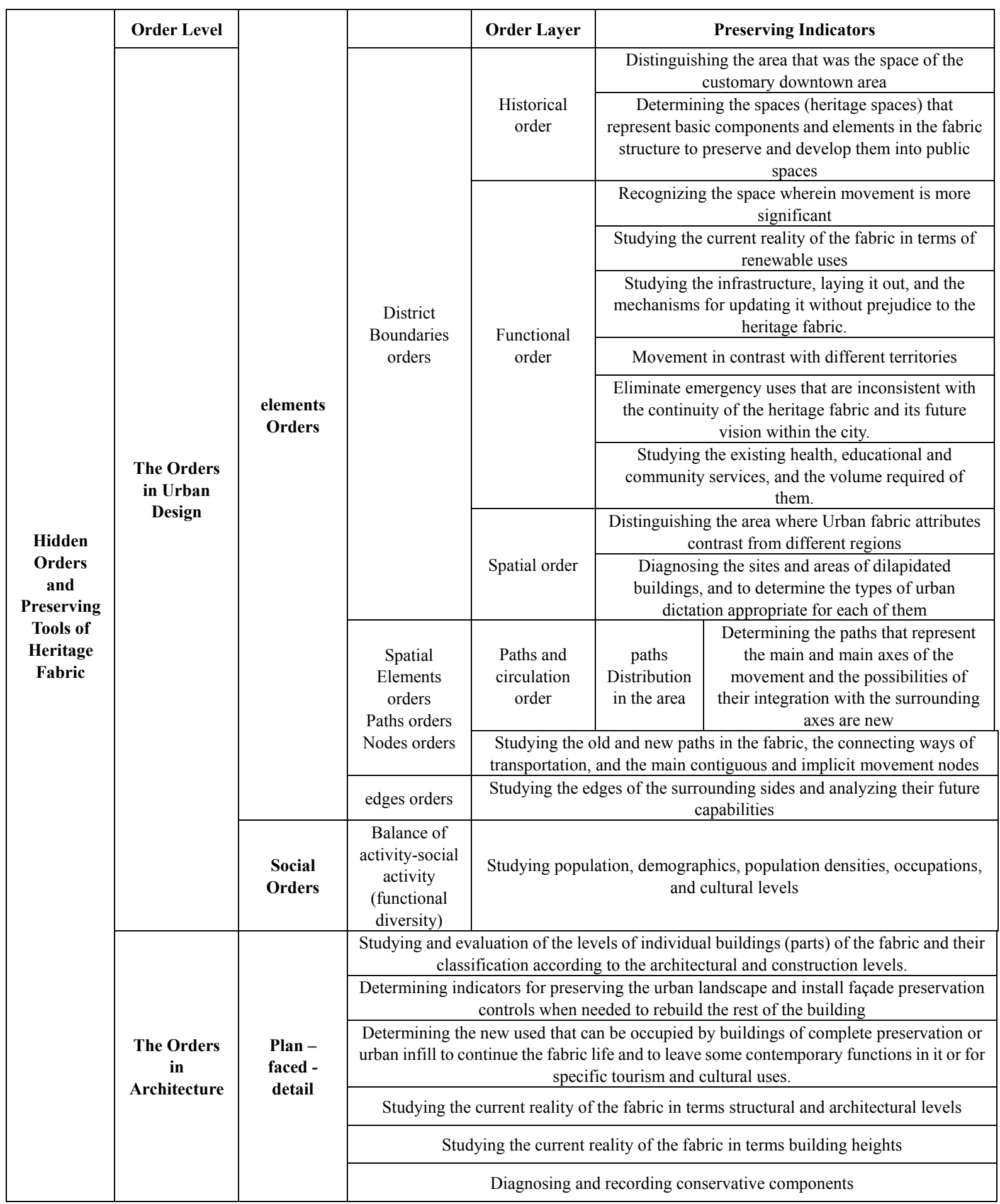

\subsection{History of District}

Abu Jaafar al-Mansur transferred the markets from his round city to al-Karkh, which was crossed by the Karkhaya River, and al-Mansur ordered the construction of Al-Karkh in the year fifty-seven and a hundred (157) $\mathrm{AH}$, in which the markets were transferred from
Al-Madinah (Al-Mawdawara) and Al-Sharqiyah to Bab Al-Karkh, Bab Al-Shair and Al- Muhawhal, which is the market Known as Al-Karkh.. It was said: The reason for transporting them to Al-Karkh is that their smoke rose and the walls of the city became black and Al-Mansour was harmed by it, so he ordered them to be transported. Al-Karkh markets were established on the southern side of 
Baghdad, between the Sarat River and the Issa River, and to be a center for economic activity, even if Baghdad expanded, then Karkh became In its midst, a mosque and housing was built for the people of the markets so that they would not enter Baghdad, and in it the roads and ties of the city were expanded and placed on a measure of forty cubits, see (figure 6). Each craft or trade had its separate market or path, and between the markets of Karkh there was a market for fruits, a market for cloth, a food market, a market for money changers, a market for papers, and a market for sheep, and construction expanded in Karkh so the Isa River extended to it, which remained the southern border separating the city. The population was crowded in Al-Karkh, and there were many business owners, merchants, and scholars in particular, and Al-Karkh was like the spring of a round city. And it is noticed that Al-Mansour in the year $157 \mathrm{AH}$ held the bridge at Bab Al-Shaeir. The purpose of holding this bridge was to facilitate business by connecting the two sides.

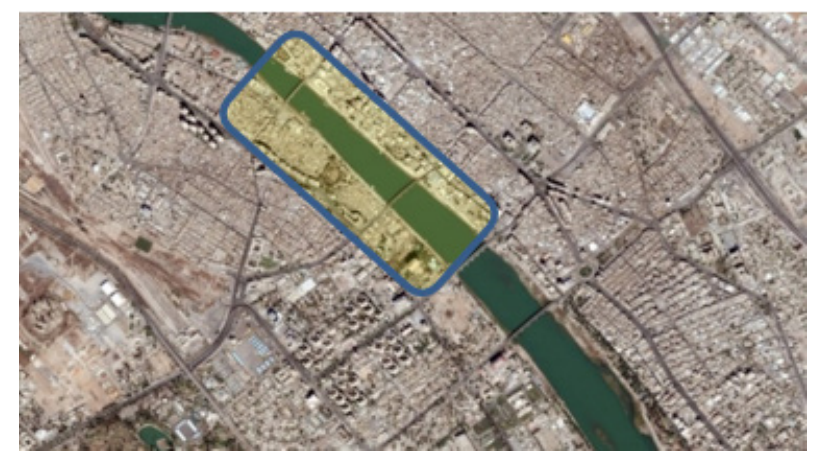

Figure 3. A satellite image of the study area Al-Shawaka, Bab Al-Seef and Al-Karimat
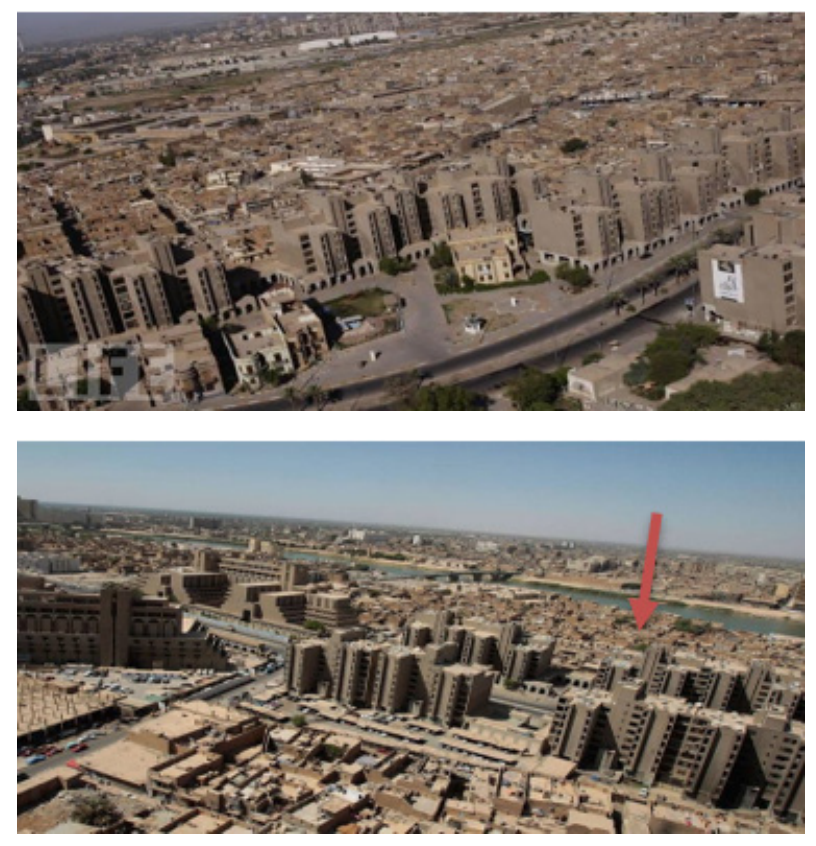

Figure 4. Al-Shawaka district behind Haifa St. residential buildings

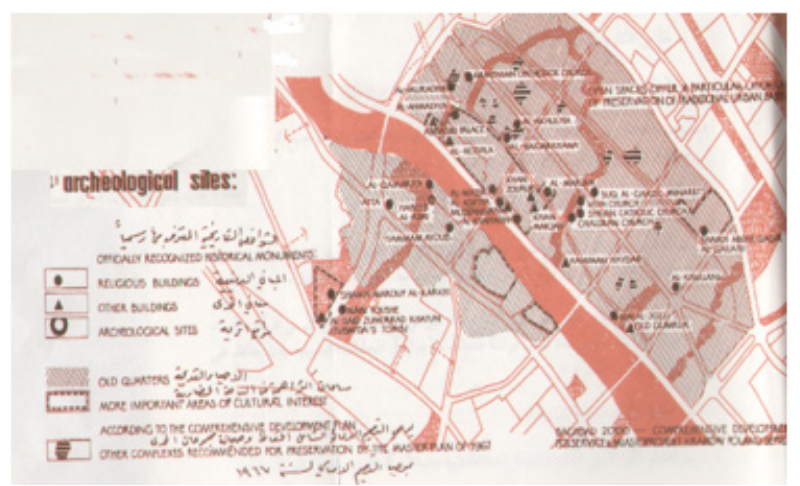

Figure 5. Al-Shawaka from Historic Important Areas, Source Paul Service, master plan for 1967.

Many believe that Al-Karkh is the current western side between the locality of Al-Ja' fir and Al-Karimat, although Al-Karkh was a large locality in the southwest of the city of Mansour, and extends around the course of the Isa River towards the east until it is close to the Tigris above Al-Ja'fer, so the Sharia that was at the top of Al-Ja'fer was called (Al-Karkh Legislature), currently the site of the Beiruti cafe, and Al-Astakhari and Ibn Hawqal are called the entire western side under the name Al-Karkh, referring to the most important locality in it, Al-Karkh, and they mention that this shop is the most vital store in Baghdad. [19] See (figure 7, 8).

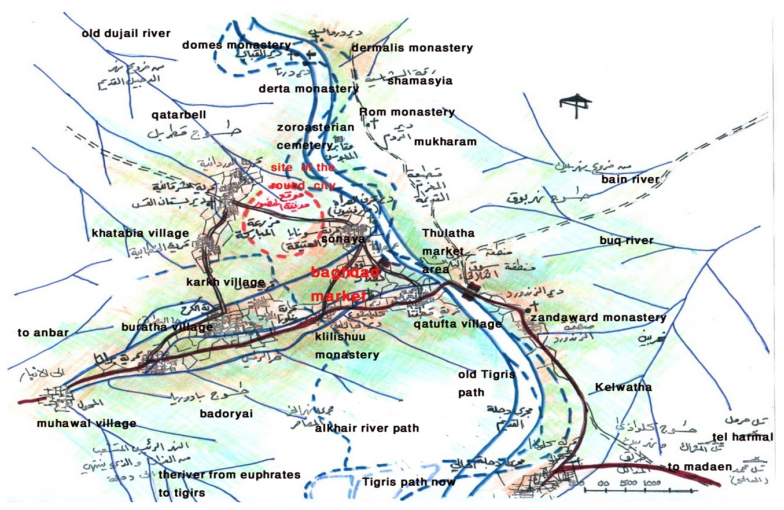

Figure 6. A map of Baghdad city at the beginning of the Abbasid era (150-334) AH (767-946 AD) illustrates the basic relationships of paths (axes) and interconnections in Baghdad region [20]

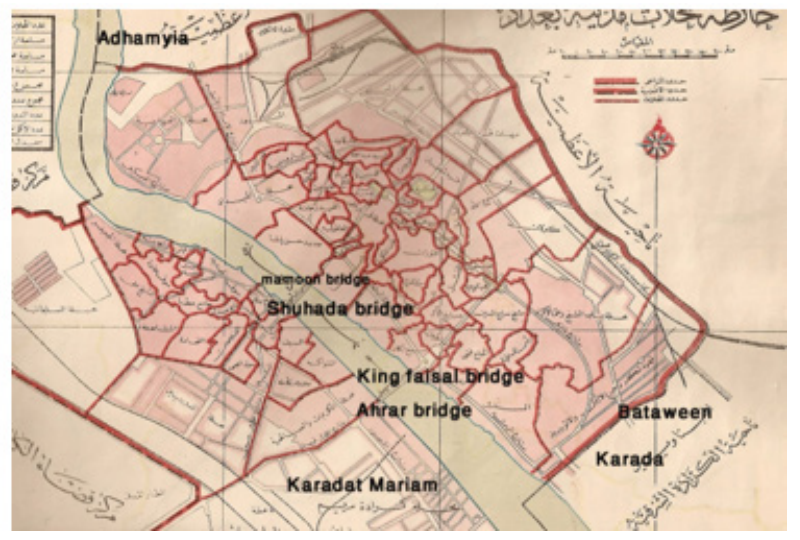

Figure 7. Al-Karkh and Al-Rusafa, at the beginning of the twentieth century, which appears Mahalla in the old Al-Karkh: Al-Shawaka, Bab Al-Seif and Al-Karimat [19] 


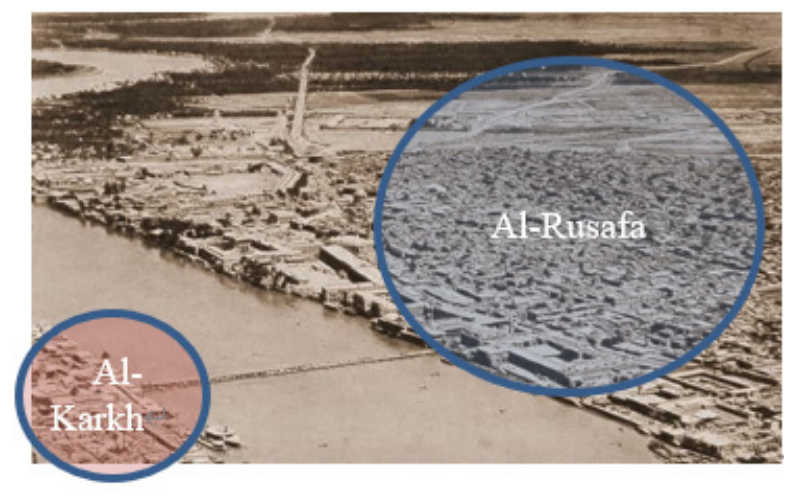

Figure 8. Al- Shuhada Bridge connects Rusafa with Karkh, showing the Al-Shawaka market, Sharia, Bab Al-Seef

There were on the Isa River between the Mawhar and the Tigris ten arches, including the Arch of the Thorns (the place of the sellers of thorns) and the Qantarat of Bani Zureik, and between them on the east are the Arch of the Thorns, and on the west of the Arch of the Thorns also four arches, where it was mentioned that Caliph al-Mu'tasim built sugar at the mouth of the Isa River in $653 \mathrm{AH}$ to increase water to reach a new palace near the arch of thorns, and there was a market around each of these ten arches.

The research problem lies in analyzing the heritage orders from the heritage urban fabric in the old Karkh from Baghdad city, through pictures. See (figure 9, 10, 11, $12,13,14,15,16,17)$.

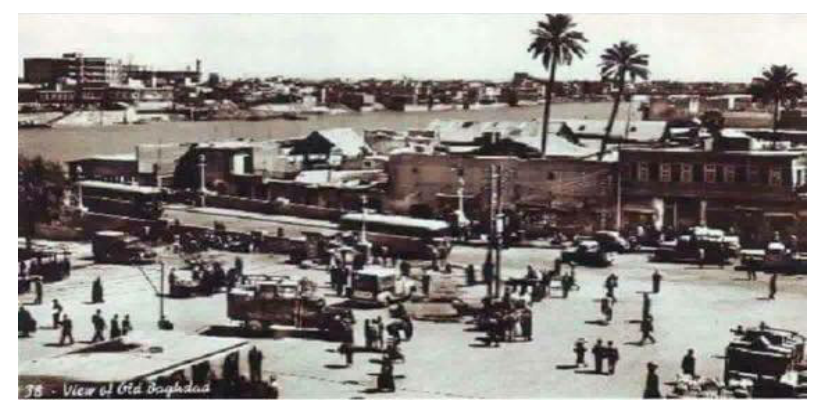

Figure 9. Al-Shuhada Bridge on the Karkh side, showing the bus stop, and on the other side a part of Al- Shawaka market that was removed and became a parking lot for the Pension Department's cars

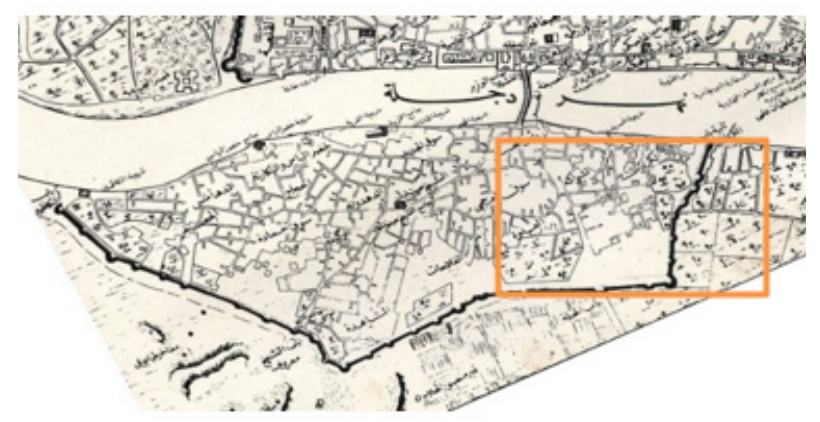

Figure 10. Old Al-Karkh 1855

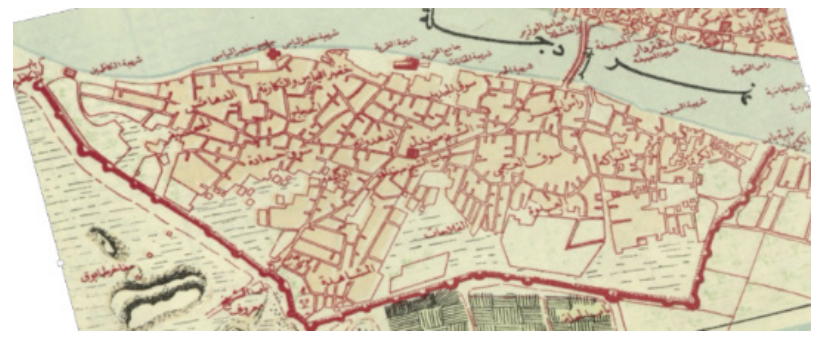

Figure 11. Al-Karkh from a map of Baghdad, Felix Johnson 1853-1854 [21]

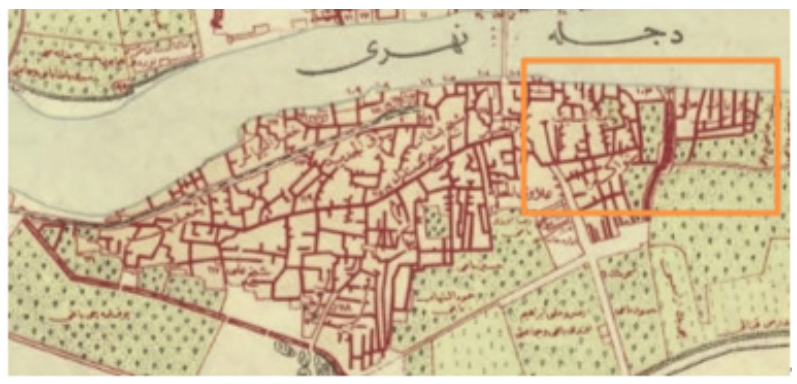

Figure 12. Map of ancient Karkh as drawn by Rashid Khoja, Chief of Staff of the Ottoman Army, 1908 [21]

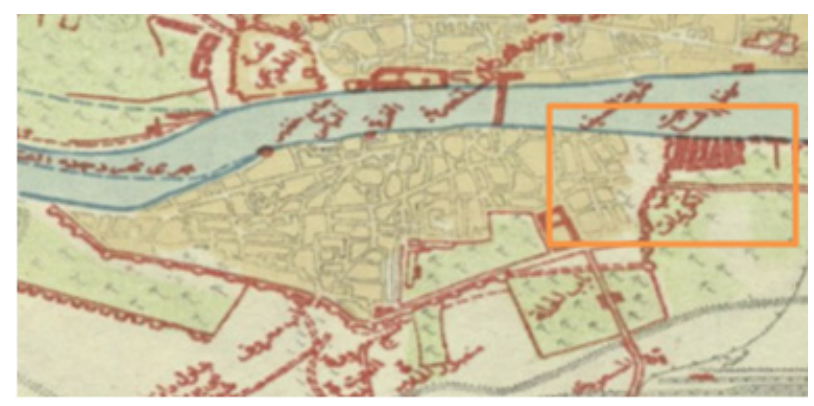

Figure 13. Al-Karkh, early twentieth century, drawn by Saar and Herz Field [21]

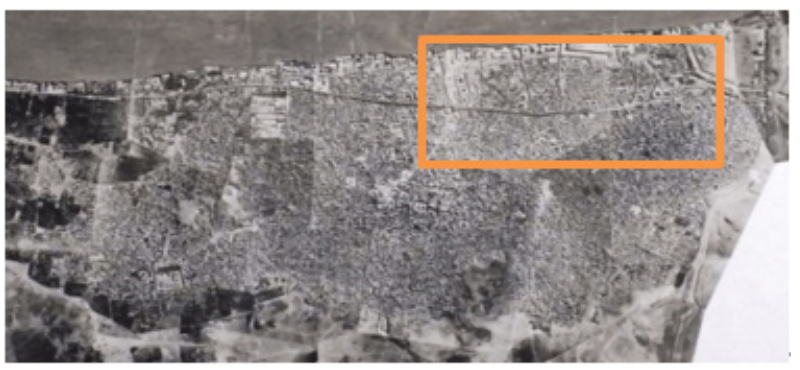

Figure 14. Aerial photograph showing old Karkh - BAGHDAD - IRAQ in 1917 (Retrieved from https://i1.wp.com/dislocatingtheorient.parisnant erre.fr/wp-content/uploads/2016/05/fig-8.4-png-1.png?zoom=1.6875\&fit $=800 \% 2 \mathrm{C} 613 \& \mathrm{ssl}=1$ )

\subsection{Al-Shawaka Neighborhood}

(Darbouneh) is a Baghdadi term given to the narrow path in the old alleys of Baghdad, (Darbouneh) as it is a miniaturization of the word (path), and it is a narrow secondary lane or alley, and it is also a road open from both sides that is sufficient for a foot and an animal, or it is a word that descended from (Dar Abouneh) meaning 
the house that Man grows up and thrives, and the Baghdadi people inherited the habit of miniaturizing words from the Arameans, so they said: Bazunah (Basina), Zaydun (Zaid), Saadoun (Saad) and Zgheroun (Saghir)... etc., see (figures 14, 15, 16).

From the alleys of Bab Al-Seef neighborhood, Baba Zinko alley adjacent to (Al-Baghi) alley and the alley of Al-Mawla, and in Al-Karimat neighborhood. What is striking is that there is an alley in this neighborhood called "Akkad Al-Jalabah" meaning the dog. And the boys from the presence of a dog in one of the houses alley.

The names of alleys when you are coming from Al-Shuhada Square, the first branch on the right is called (Al-Fouk) alley, which extends to the Ministry of Tourism building, then after that comes a street on the left called (Al-Jeben Suq) Street for the wholesale, then the first branch on the left is ( Al-Gilawi) alley, which is a closed-end branch, and the second is called Al-Baghi alley, the third is Bab Al-Seef and the fourth is called Al-Shawaka alley, and the fifth is Darbouneh Al-Jadih, which runs parallel to the British embassy.

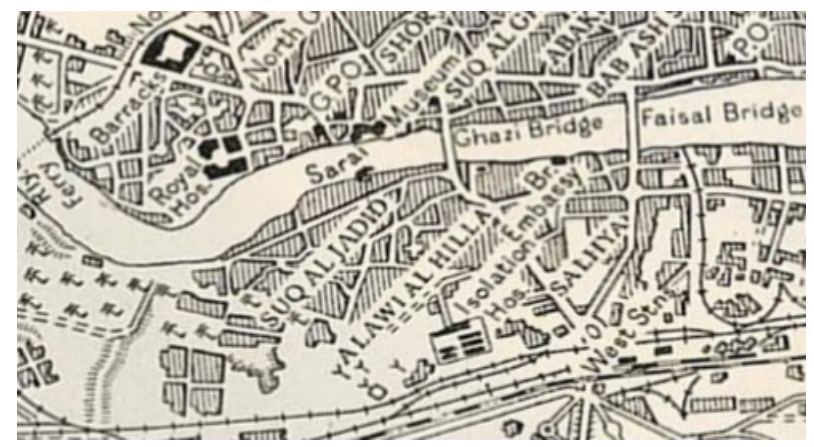

Figure 15. Al-Karkh-BAGHDAD - IRAQ 1944

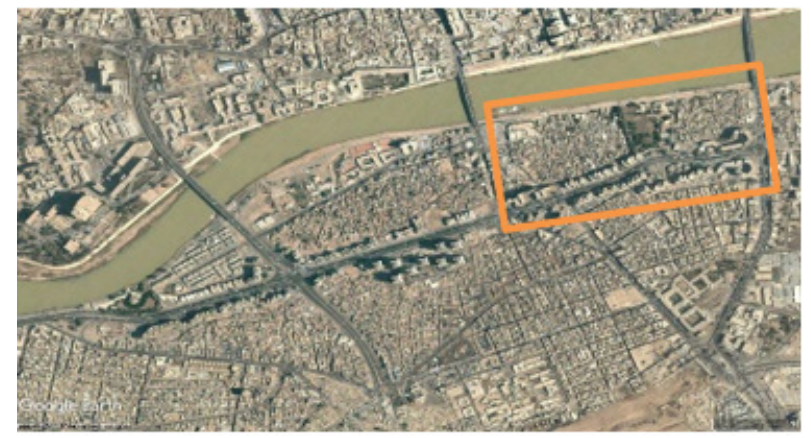

Figure 16. Al-Karkh - BAGHDAD - IRAQ in 2004

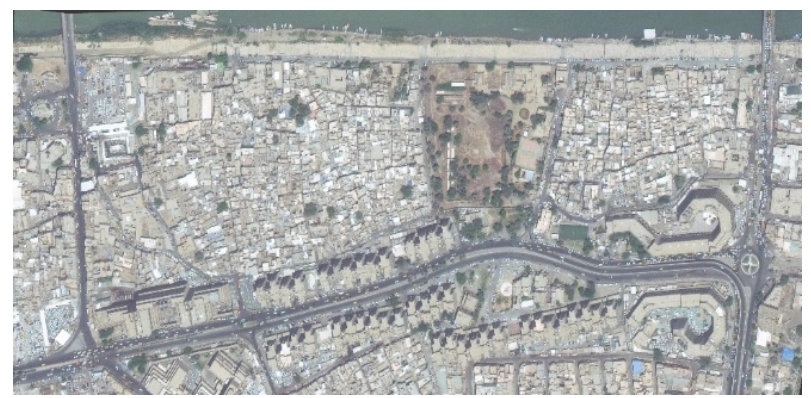

Figure 17. Al-Shawaka in Al-Karkh in 2020

\subsubsection{Al-Gilawi Alley}

Al-Gilawi alley, the name through the first inhabitants of it where their origins were from the people of Dujail so they were in Dujaili, then it was abbreviated to Gilawi, and it was the first house that was built so it was named after him. It is not open (cul de sac) and it is stretching to the near of the General Retirement building. See (figures $18)$.

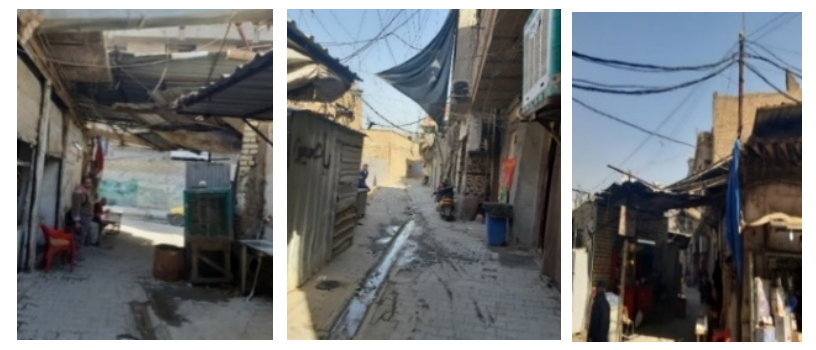

Figure 18. Al-Gilawi alley

\subsubsection{Bab Al-Seef Alley}

$\mathrm{Bab} \mathrm{Al}-\mathrm{Seef}$ is the name of a well-known place in the Karkh region, as the river's shore was a place to receive ships carrying goods and grains, and Bab Al-Seef was the place where cargo, especially grains, were stored. It is described as the large commercial port of Baghdad on the Tigris River in addition to the other Baghdad laws, which were secondary places for unloading some of the small ships and clack ships whose loads are transferred to the basement and distributed between Baghdad areas in Karkh and Rusafa, see (figures 19, 20).

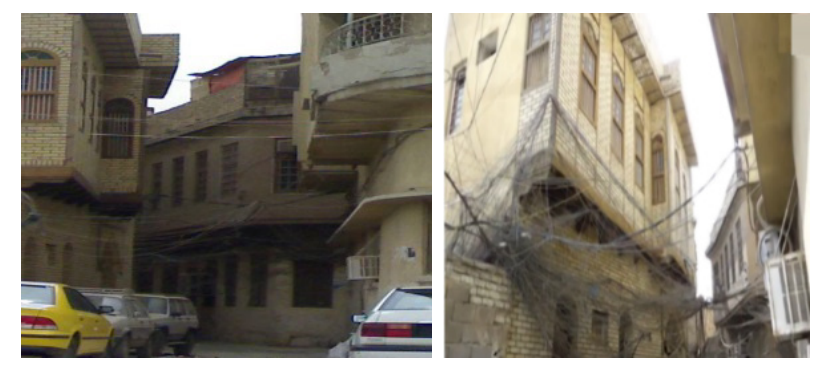

Figure 19. Entrance to $\mathrm{Bab} \mathrm{Al}$-Seef from the side of the (river) to achieve directivity
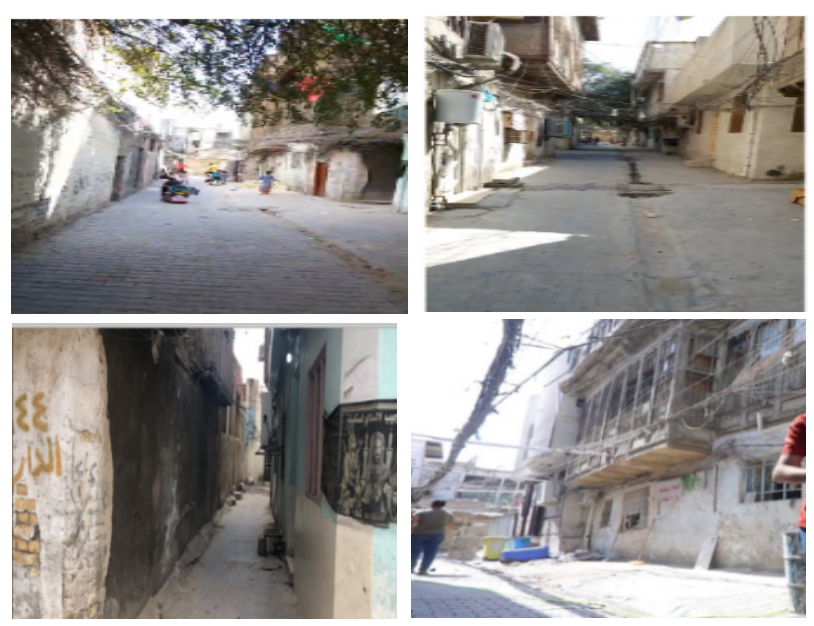

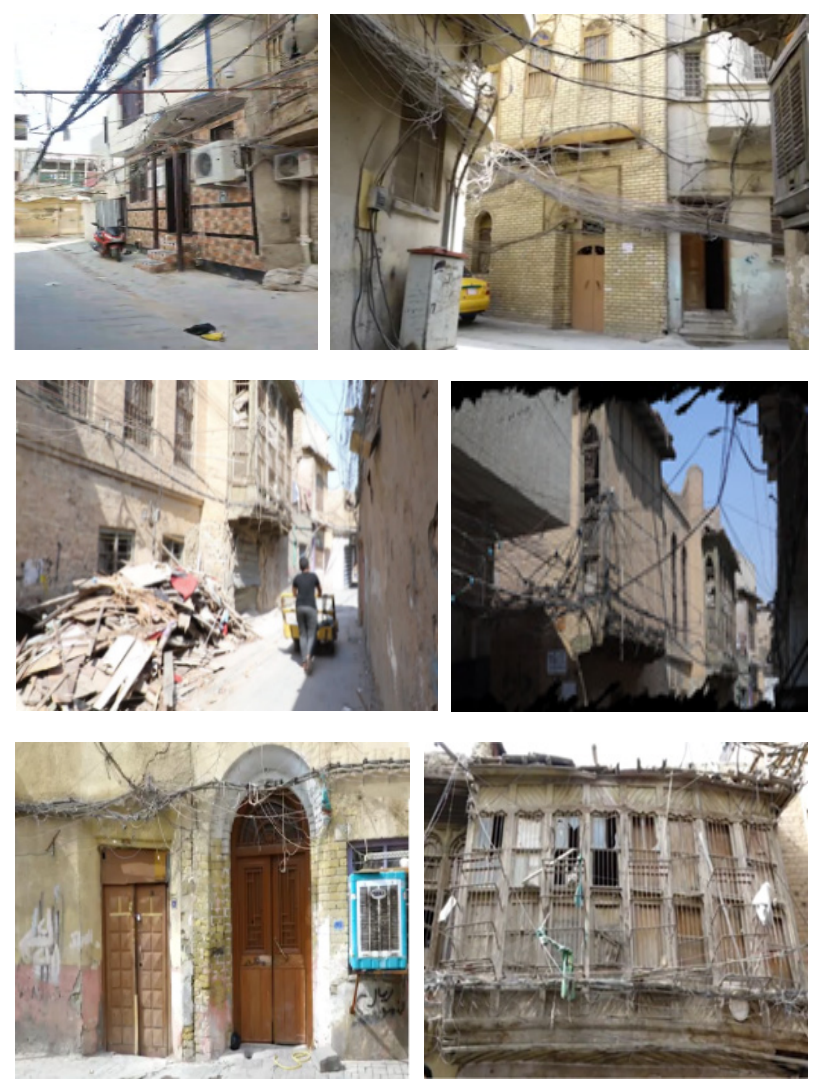

Figure 20. Bab Al-Seef alley A wide range of orders through a variety of patterns and styles

\subsubsection{Al-Baghi alley}

From the closed-end alleys, it was called al-Baghi, because it was like a garden, so it was called Al-Baghi in Persian. (Figure, 21, 22, 23).
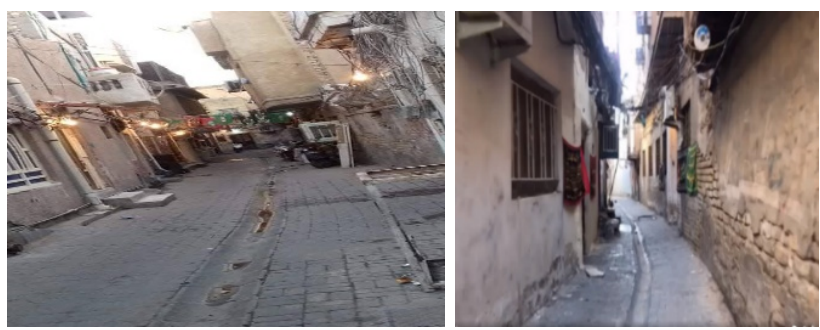

Figure 21. Al-Baghi alley Lack of space balance between the blocks of buildings and the surrounding areas Date 2016
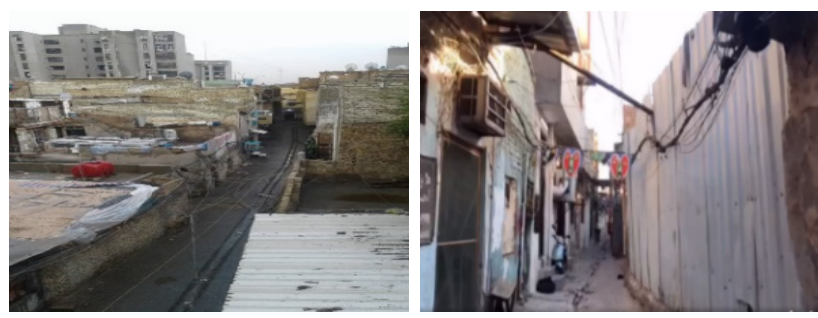

Figure 22. One of branches of the closed Al-Baghi alley
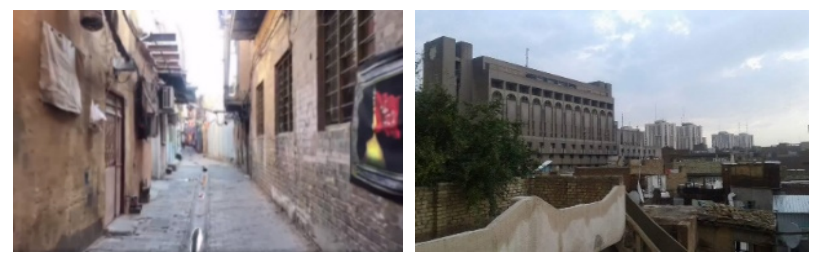

Figure 23. A view of the Haifa buildings from Al-Baghi alley. Photo date $/ 2016$

\subsubsection{Baba Zinko alley}

This alley was named after a righteous man named (Baba zinko) and it seems that he was an Indian. He was one of the righteous men who were close to God Almighty, and he had apparent dignities, and he mentioned that he entered his house and did not go out, and this is why it was said in the proverbs of Baghdad (Baba Zinko, fear what happened) and that he died and did not feel One of his death, then they built a grave in his (his absence) place, so they said the parable, and the tomb was demolished in addition to the sword and the market next to it, and the famous Beiruti café next to the sword and the bridge bath, during the reign of Taher Yahya's government during the time of President Abdel-Salam Aref in (1964), and a building was built in its place. Public retirement and parking lot. [22]. See (figure, 24, 25, $26,27)$.

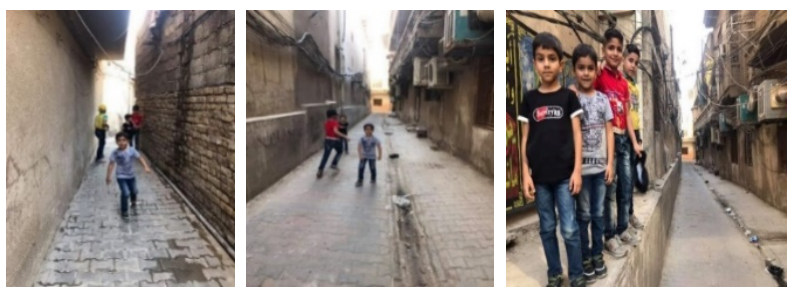

Figure 24. Entrance to Baba Zinko alley from the retirement side, from the Al-Shuhada Square side, the retirement building wall

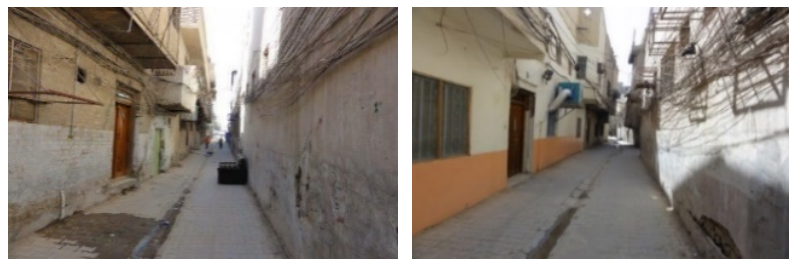

Figure 25. Baba Zinco alley in Bab Al-Seef, heading towards Al-Shuhada Square. The wall is the back façade of the retirement building

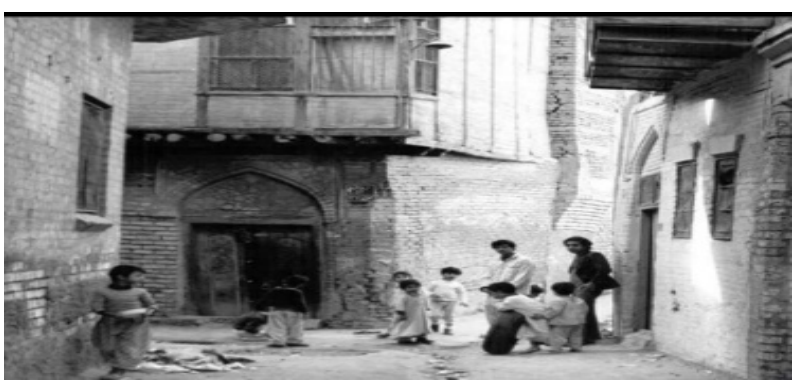

Figure 26. A picture in the fifties of $\mathrm{Bab} \mathrm{Al}-\mathrm{Seef}$ area, the corner of Husseiniya Al-Hunud Al-Dahra, on the left is the beginning of Baba Zinko, adjacent to the Husseiniya Al-Hunud and opposite alley, Salman Al-Karwi house 


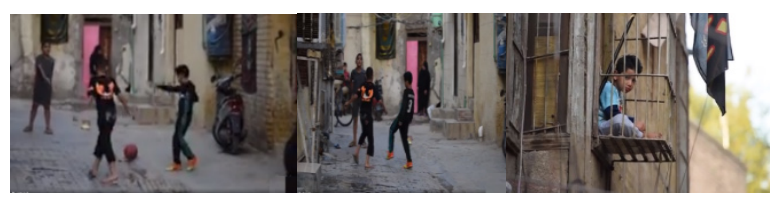

Figure 27. Darbouneh Al-Bita in Bab Al-Seef

\section{Conclusions}

The people of the region suffer from the following problems:

- Old homes devoid of the features of modern and comfortable life for their residents and the lack of cleanliness.

- Neglecting, poor services, and the presence of groundwater.

- Solving the problem of power outages

- Cleaning the riverbank, the municipality's interest in the area more, and removing excesses

- Housing worthy of people and suitable for the current time, while preserving the region's heritage.

- Finding material facilities and good job opportunities for the people of the region.

- Building model schools with paving roads.

- The order is on several levels, order of the building, which is the architectural order. As for the urban order, it includes the structural order, space and mass, from which the order of paths (alleys) is produced as well as the order of nodes (spaces), the visual order (urban townscape).

- It can be benefit from the facilities and the structures of old buildings in contemporary service, activities, and events.

- There is a balance in useing of the land in terms of the predominance of residential use, and this is a good indicator.

\section{Recommendations}

- Preserving the identity and collective memory of Heritage Fabric as an integral whole.

- Preserving the alleys and their urban townscape by repairing and taking care of lost or worn out heritage parts.

- The development of historical paths towards the river.

- The development of industries and heritage jobs in the region, such as making ropes, river boats and selling fishing materials.

- Creating spaces linking traditional and heritage spaces with modern spaces.

- Maintaining the residential use of the area between the two bridges and that the commercial use is restricted to serving the people of the area.
- The development of the riverfront, the opening of communication lines for river tourism, the revival of the Beiruti café, and the addition of new places as restaurants.

- The use of the demolished buildings as a museum of ancient professions in the area, as well as pictures of political and artistic figures.

- Developing the infrastructure of the area while respecting the existence of these narrow alleys.

- Preserving the historical urban landscape through the repair and restoration of the facades, even if the horizontal plan is modern.

- Difficulty in the mixed use of heritage fabric. Difficulties in traditional environments, because society has conservative customs and traditions that prevent some uses.

- Choosing the appropriate and specific uses and in specific places such as the riverfront that may be visited by tourists from different places such as cultural centers, museums and other uses that are exposed to the privacy of residents and what this may cause in terms of societal objections that restrict the type of work and its characteristics.

- Reviving the khans that existed in the area through the use of traditional elements. Inventorying the demolished houses and rebuilding them with new plans in which we use historical elements, carrying out the urban dictation process.

- Maintaining the alleys and the open spaces that connect the alleys.

- Protection and maintenance of the traditional urban fabric and the distinguished historical characteristics it contains, along with the existing social life style .

- The status of the archaeological buildings in terms of their relations with the buildings and the spaces surrounding it, in terms of preserving the human scale.

- A conscious study such as planning, designing, and constructing destroyed buildings in a manner that achieves a balance between the material needs and the needs that preserve this continuity.

- Preserving the sky line forming the old (heritage) area in terms of heights, external formation, lighting, and color.

- Human building and different living standards (culturally) represented by the difference in living habits, in addition to the hypothesis to develop thought to deal with the method of linking the cultural heritage from the application and then the legislative aspect that guarantees its survival and continuity.

- Preserving the harmonious general unity in planning each city and taking into account the architectural environment in its main characteristics, especially in the old archaeological areas, through new legislative rules that guarantee the harmony of the new with the old. 
- Determines the criteria for the relationship between the heritage fabric and the neighborhood in terms of accessibility, degree of integration, and the link between the heritage fabric and its surroundings.

- Working to evacuate spaces, modifying and developing some uses, assessing and renewing infrastructure, facilitating accessibility.

- Tools of rules and regulation of construction and urbanization and the legal and legislative framework.

\section{Acknowledgments}

This article is prepared in the context of $\mathrm{PhD}$ thesis with the title of "The Hidden-Orders in the heritage fabric in Iraq" studied in - University of Baghdad, College of Engineering- Architecture Department.

\section{REFERENCES}

[1] Karatosun, Müjgan Bahtiyar and Deniz Çakar. "Effects of Cittaslow Movement on Conservation of Cultural Heritage: Case of Seferihisar \& Halfeti, Turkey" Civil Engineering and Architecture, Vol.5 No. 3, pp.71-82, 2017. DOI:10.13189/cea.2017.050301

[2] Damla Misırlisoy , "New Designs in Historic Context: Starchitecture vs Architectural Conservation Principles," Civil Engineering and Architecture, Vol. 5, No. 6, pp. 207 214, 2017. DOI: 10.13189/cea.2017.050602.

[3] Al Slik, Ghada, Al-saffar, Maitham "The sustainable urban development in Al_Kharkh historic center" Journal of Engineering, Baghdad, Iraq, 20 (11), pp.1-28, 2014. Retrieved from https://www.researchgate.net/publication/346966170_The_sustain able_urban_development_in_Al_Kharkh_historic_center. (accessed December ,13, 2020).

[4] https://en.wikipedia.org/wiki/David_Bohm.

[5] Kuilman, Marten, "Quadralectic Architecture - A Panoramic Review. 2013. Retrieved july 2o, 2020 from the https://quadralectics.wordpress.com/5-essentials/.

[6] Bohm, David, peat, David, "science order and creativity" A Bantam Book, library of Congress, 1987, p.131.

[7] Johnson, Paul-Alan, "The Theory of Architecture: Concepts Themes, Practices, Order" Chapter six, "The Imposition of Human Constructs", John Wiley \& Sons, 1994, p.234.

[8] Ching, Francis, "A Visual Dictionary of Architecture" John
Wiley \& Sons, Canada, 1995, p.179.

[9] Kahn, Louis, "Order and Form" Yale School of Architecture, Perspecta, Vol. 3, pp. 46-63, 1955.

[10] Hanson, J., "Order and Structure in urban Design: the plans for the rebuilding of London after the Great Fire of 1666". In: Ekistics, Vol. 56 (334-335), p.22. 1989.

[11] Arnheim, Rudolf, "The dynamics of architectural Form" Berkeley: University of Califomia Press.1977, p.162.

[12] Hanson, Julienne, Hillier, Bill "The social logie of spaee" Cambridge University Press, 1984, p.4.

[13] Rappaport, Amos "On the cultural orgins of settlements" In A. 1. Catanese \& J .C. Snyder (Eds.), "Introduction to urban planning" NewYork, McGraw Hill, 1979, p.35.

[14] Hanson, Julienne, "Order and Structure in Urban Space: A Morphological History of the City of London, London" University College London. Unpublished PhD Thesis. 1989.

[15] Karimi, Kayvan, "A reflection on Order and structure in urban design" The Bartlett School of Graduate Studies, University College London (UCL), The Journal of Space Syntax, vol. 3, issue: 1, p.39. 2012.

[16] Owied, Hussam Sachit, "Morphological Transformations In Historical Cities Centers" University of Baghdad, College of Engineering, Department of Architectural Engineering, $\mathrm{PhD}$ Thesis, p82. 2013.

[17] Al-Hanish, Jamila Al-Hadi, and Al-Manfukh, Abd Al-Rahman Abd Al-Salam Ali, " Heritage Buildings in City Centers and Methods of Preservation (Old City Tripoli) " for the International Journal of Science and Technology. 2017.

[18] Lynch, keven "The Image of The City" the Massachusetts Institute of Technology and the President and Fellows of Harvard College Twentieth Printime. 1960.

[19] Al-Hamwi, Yaqut, "Maejam Al-buldan" Part Four, p. (472-473), the comprehensive encyclopedia.

[20] Al slik, Ghada, "Baghdad (Madinat Al Salam) In The Islamic Civilization" Conference: Istanbul, Turkey, November, 2008. Retrieved from https://www.researchgate.net /publication/346040992_bghdad_almdynt_almdwrt_1250_am/relat ed

[21] Sousse, Ahmad, "Atlas of Baghdad" Public Survey Directorate Press, Baghdad, 1952, pp. 4-5.

[22] Al-Mada Magazine, "from Al-Karkh Stores, Bab Al-Saif and Al-Shawaka neighborhood", published on 09/16/2012. Retrieved from https://almadasupplements.com/view.php?cat=557 1, Accessed:10/21/2020.

[23] Kawther, Khawla Kareem. "Re-Pointing as Technique in Repair and Sustainable Architectural Preservation." the Iraqi Journal of Architecture, University of Technology, Vol.16 No. 2, pp.60-73, 2017. 